\title{
Prática corporal inclusiva e ludicidade na educação infantil: considerações sobre o professor e sua formação
}

\section{Body and inclusive practice playing in early childhood education: considerations for the teacher and her training}

\author{
Daiana Camargo* \\ Silvia Christina Madrid Finck ${ }^{* *}$
}

\begin{abstract}
Há o sofrimento do corpo, em si mesmo: dores, incapacidades, limitações. Mas há a dor terrível do olhar das outras pessoas. Se não houvesse olhos, se todos fossem cegos. Então a diferença não doeria tanto. Ela dói porque, no espanto do olhar dos outros, está marcado o estigma da maldição: "Você é diferente".
\end{abstract}

Rubem Alves (1999)

Resumo: Este artigo se caracteriza como uma revisão bibliográfica e tem por objetivo discutir aspectos relacionados à Educação Infantil numa perspectiva inclusiva. Para tanto, apontamos as atividades corporais como possibilidades e a ludicidade como meio para atender às diversidades dos alunos e suas potencialidades, na busca da construção do conhecimento e da formação humana. Refletimos, no texto, sobre o corpo como meio de expressão e aquisição de conhecimentos, através de um fazer pedagógico pautado na interação e sua contextualização na educação das crianças. Na sequência, discutimos sobre as práticas inclusivas na Educação Infantil; em seguida, evidenciamos aspectos relacionados ao corpo, ao movimento e à educação inclusiva na formação inicial do professor da Educação Infantil, destacando a necessidade de uma prática pedagógica contextualizada e da formação continuada na busca de soluções. Expomos também algumas ideias e posicionamentos acerca do processo de formação docente, que percebemos como insuficiente para atender às especificidades relacionadas à inclusão. Finalizamos o texto apresentando algumas considerações, a nosso ver relevantes, sobre a temática enfocada.

Palavras-chave: Educação Infantil. Inclusão. Corpo. Formação de professores.

Abstract: This article presents a literature review and aims to discuss issues related to Early Childhood Education from an inclusive perspective. To this end, it demonstrates physical activities and playfulness as possibilities to meet the diversity of students and their potential in the pursuit of knowledge construction and human development. In the article it is argued that teachers must act to meet the interests and needs of children, considering their experiences, being also facilitators of learning and development of students. The article discusses the importance of physical activity and playfulness for child development; the body

\footnotetext{
* Mestre em Educação (UEPG) e professora colaboradora da UEPG. Email: camargo.daiana@ig.com.br

** Doutora em Ciência da Atividade Física e do Esporte (UNILEON/ES). Professora do Curso de Licenciatura em Educação Física e do Programa de Pós-Graduação em Educação. Email: scmfinck@uol.com.br
} 
is seen as a means of expression and acquisition of knowledge in early childhood education through pedagogical practices based on the interaction and contextualization toward the education of children. Another aspect discussed is inclusive practices in early childhood education and inclusive education in teacher training, highlighting the need for contextualized pedagogical practices and continuing training as it seems that initial education is insufficient to meet the specific needs related to inclusion. The final part of the article presents relevant considerations on the theme addressed.

Keywords: Early Childhood Education. Inclusion. Body. Teacher Training.

\section{Introdução}

A infância certamente é a fase da vida do ser humano em que o movimento é vivenciado de forma mais intensa, pois mover-se, expressar-se através do corpo, de uma linguagem corporal, é natural nas crianças. Através do movimento a criança se expressa, se comunica, interage, brinca, se desenvolve e aprende. Para a criança, movimentar-se é tão importante quanto se alimentar e dormir, é vital para que seu desenvolvimento seja pleno. Mas, será que a escola considera essa necessidade da criança?

Quando voltamos nosso olhar para a escola, percebemos que o tempo de movimentação das crianças é bastante reduzido: limita-se ao horário do recreio, às aulas de Educação Física (quando as crianças têm), ou àqueles momentos destinados para "brincar”. Mas se o movimentar-se é vital para a criança, por que na escola tal necessidade não é devidamente considerada? Por que o professor não percebe corporalmente a criança?

Este artigo se caracteriza como uma revisão bibliográfica e tem por objetivo discutir aspectos relacionados à Educação Infantil numa perspectiva inclusiva. Para tanto, apontamos como possibilidades as atividades corporais e a ludicidade como meio para atender às diversidades dos alunos e suas potencialidades, na busca da construção do conhecimento e da formação humana. Discutimos ainda que o professor no desenvolvimento da prática pedagógica deve priorizar os interesses e as necessidades das crianças, considerando suas vivências, sendo também um facilitador da aprendizagem e do desenvolvimento dos seus alunos.

No texto, primeiramente fazemos uma abordagem sobre a importância da atividade corporal e da ludicidade para o desenvolvimento infantil. Refletimos sobre o corpo como meio de expressão e aquisição de conhecimentos, através de um fazer pedagógico pautado na interação e sua contextualização na educação das crianças. Na sequência, discutimos sobre as práticas inclusivas na Educação Infantil; em seguida, evidenciamos aspectos relacionados ao corpo, ao movimento e à educação inclusiva na formação inicial do professor da Educação Infantil, destacando a necessidade de uma prática pedagógica contextualizada e da formação continuada na busca de soluções. Expomos também algumas ideias e posicionamentos acerca do processo de formação docente, que percebemos como insuficiente para atender às especificidades relacionadas à inclusão. Finalizamos o texto apresentando algumas considerações, a nosso ver relevantes, sobre a temática enfocada. 


\section{A atividade corporal, o lúdico e o de- senvolvimento infantil}

Analisando a complexidade do ser criança, devemos considerar que seu desenvolvimento integral e suas possibilidades de construção de conhecimento estão diretamente relacionados às suas vivências e à qualidade destas em seu meio social e, consequentemente, no ambiente educacional. O ambiente em que a criança está inserida deve possibilitar a ela as mais diversas e diferenciadas formas de interação e convívio, rompendo assim com a tradicional prática pedagógica de fragmentação do ser e da negligência em relação à atividade corporal. Moyles (2002, p. 12) ressalta que:

O brincar em situações educacionais, proporciona não só um meio real de aprendizagem como permite também que os adultos perceptivos e competentes aprendam sobre as crianças e suas necessidades. No contexto escolar, isso significa professores capazes de compreender onde as crianças “estão” em sua aprendizagem e desenvolvimento geral, o que, por sua vez, dá aos educadores o ponto de partida para promover novas aprendizagens de domínios cognitivos e afetivos.

Diversos são os estudos em educação e psicologia que abordam as características e especificidades do desenvolvimento infantil (CARVALHO, 2003; DELVAL, 1998; LE BOULCH, 2008; OLIVEIRA, 2002), os quais consideram cultura, ambiente social, interação, entre outros fatores que afetam, ou podem afetar o adequado percurso de desenvolvimento saudável da criança.

Delval (1998) aborda os estudos piagetianos acerca do desenvolvimento e da aprendizagem infantil, nos quais o pesquisador Piaget retrata as intensas caracterís- ticas lúdicas e motoras que são percebidas principalmente nos primeiros anos de vida, as quais caracterizam a primeira forma de interação do novo ser com o meio que lhe é completamente estranho e repleto de estímulos. De acordo com Delval (2001, p. 17):

Desde o nascimento e mesmo antes, a criança está sujeita a influência da sociedade onde vive. Por meio dessa pressão social, sofrendo-a e reagindo diante dela, ou seja, interagindo com o meio, chegará a se tornar um membro da sociedade adquirindo modelos de conduta que são característicos da mesma. Aprenderá a comportar-se como os adultos nessa sociedade. Aprenderá a sua linguagem e a sua cultura.

Oliveira (2002, p. 124) enfatiza que "progredir em direção da autonomia significa para a criança construir e coordenar esquemas de ação, noções e representações que lhe possibilitam, no processo de desenvolvimento, realizar e compreender as coisas por si mesmas".

Segundo Le Boulch (2008, p. 129), “é pela atividade do corpo, suporte da ação, em interação com a linguagem, que se realizará a harmonização entre o afetivo e o cognitivo, e não pela razão ou magia do verbo". Entretanto, a atividade corporal - elemento naturalmente constitutivo da criança e essencial ao seu desenvolvimento e aprendizagem - foi, ao longo da história da educação, desprezada em escolas que, "impregnadas de formas de dominação e poder" (FOUCAULT, 2007), fazem com que o ambiente escolar adquira forma sombria, triste e excludente.

A partir do século XVIII, com os estudos direcionados à compreensão da criança, a educação recebe novas influências teóricas que modificam gradualmente a forma de trabalho dirigido à infância. Nessa época ocorreram movimentos isolados 
direcionados à pequena parcela da população infantil, os quais foram de grande valia para que se desse início à construção de uma identidade para uma educação voltada às crianças e às suas especificidades, as quais são diferenciadas das do adulto.

De acordo com Cambi (1999), a partir dos estudos de Rousseau a pedagogia passou a ser puericêntrica, isto é, passou a ter a criança como centro da prática pedagógica, tendo como eixo de estudo um conjunto de técnicas para o seu desenvolvimento integral.

Arce (2002) enfatiza que os estudos de Froebel (1826) se tornaram uma das vertentes teóricas importantes que deram sustentação à utilização do brincar na Educação Infantil, fundamentando documentos e projetos pedagógicos ao longo dos anos. A contribuição da obra de Froebel pode ser destacada como básica para a configuração da Educação Infantil nos moldes que a vivenciamos contemporaneamente.

Cambi (1999) e Oliveira (2002) destacam as contribuições de Montessori (1870-1952) e Decroly (1871-1932) para a educação das crianças. Montessori criou um método fundamentado nas atividades sensomotoras da criança, desenvolvidas por meio de atividades da vida prática, como o comer, o vestir, entre outras, e enfatiza ainda a importância do equipamento escolar ser adaptado à criança e a relevância do brinquedo para a aprendizagem. Decroly, por sua vez, a partir da observação de crianças com problemas mentais, embasou seus estudos nos denominados centros de interesse, na autoavaliação e na formação para a vida, destacando também a importância dos jogos na aprendizagem. Bujes (2001) enfatiza que tanto Montessori quanto Decroly transferem suas experiências do campo da Educação Especial para a Educação Infantil.
Tais estudos foram fundamentais para subsidiar a construção de encaminhamentos pedagógicos adequados para o desenvolvimento da prática pedagógica na Educação Infantil, tanto no que se refere às características lúdicas necessárias para a construção do conhecimento infantil como à produção de material didático atrativo.

Verificamos que, apesar dos estudos específicos, a Educação Infantil incorporou toda a estrutura rígida e punitiva do já estabelecido sistema educacional, abandonando na maioria das vezes os referenciais específicos à compreensão do desenvolvimento e do aprender infantil. O lúdico, o corpo e as diferenças entre as crianças acabam se perdendo diante de um sistema massificante, direcionado a uma lógica capitalista, excludente, seletiva e racionalista, em que o ambiente, as emoções, os sentimentos e prazeres são renegados. Delval (2001) enfatiza que é na primeira etapa da vida, denominada infância, que a criança constrói as estruturas intelectuais que permitirão que ela se torne indivíduo adulto, capaz de agir sobre a natureza e interagir com os outros.

O lúdico engloba uma ampla gama de elementos infantis: o movimento, o brincar, a fantasia, a interação e a linguagem, que se constituem em fundamentos para a construção de uma educação da infância. Kramer (1993) ressalta a necessidade de construção, na escola, de um projeto político-pedagógico direcionado à realidade na qual e criança está inserida, ao contexto em que se constrói determinado ambiente educativo, enfatizando a interdisciplinaridade para a construção efetiva de uma educação desejada, coerente e denominada como integral. Moyles (2002, p. 21) afirma que:

A estimulação, a variedade, o interesse, a concentração e a motivação são igualmente proporcionadas pela situação lúdica (e também por outras). Se acrescentarmos a 
isso a oportunidade de ser parte de uma experiência que, embora possivelmente exigente não é ameaçadora, é isenta de constrangimento e permite ao participante uma interação significativa com o meio ambiente, as vantagens do brincar ficam mais aparentes.

Segundo Queiroz (2008, p. 174), “a subjetividade da criança vai se formando nas interações que estabelece com seus parceiros nos contextos cotidianos”, o que nos leva a refletir sobre a necessidade de uma prática educativa contextualizada, estimulante, agradável e significativa. Oliveira (2002) reforça os estudos em torno do ambiente educacional infantil e relata a necessidade da interação com parceiros diversos e a busca de uma identidade, constituídas num clima de segurança, autonomia e exploração, para o qual considera fundamental a exploração do lúdico, num ambiente em que os tempos escolares sejam coerentes com os diferentes ritmos de aprendizagem.

Olivier (2003) descreve as características do lúdico, apontando que o mesmo tem um fim em si mesmo, para o qual geralmente a criança não tem explicação, a não ser a do prazer que proporciona. A atividade lúdica é espontânea, pertence à dimensão do sonho, da fantasia e sensibilidade da criança, baseia-se na atualidade e privilegia a criatividade, possibilitando à criança percorrer novos caminhos, até então desconhecidos. Ao retratar a utilização da atividade lúdica na prática educativa, o referido autor relata que as dificuldades encontradas provêm do longo exílio a que a ludicidade foi submetida, repelida e desvalorizada diante da exagerada ênfase em tarefas racionais, tidas como de maior utilidade social. Há urgente necessidade de criação de um mundo onde seja permitido sonhar, onde as crianças sejam, de fato, crianças e vivam como tal.
Reencontrar o lúdico, entender seu valor revolucionário, torna-se imperativo se se deseja preservar os valores humanos no homem. Da mesma forma, através dele podemos resgatar a criatividade, ousando experimentar o novo, acordar do estado vegetativo, improdutivo, disfuncional do corpo ou da mente e escolher tornar-se homem, resistindo às experiências de vida desumanizantes, acreditando em si, em suas idéias, sonhos e visões, elementos, entre outros, percebidos como intrínsecos dos homens e da humanidade (Mello apud MARCELLINO, 2003, p. 31).

Em relação ao papel das atividades corporais contextualizadas e inseridas ao cotidiano educativo (BARBOSA, 2006; CAMARGO, 2011; CARVALHO, 2005; GARANHANY, 2006; MOYLES, 2006), constatou-se a necessidade de um estudo da criança mais direcionado a sua realidade, suas necessidades e possibilidades. Verificamos pesquisas (DORNELLES, 2005; SARMENTO, 2002; 2005; 2007; SARMENTO e GOUVEIA, 2008) que apontam a necessidade de que a criança seja ouvida e percebida como ser integrante e participativo do processo de construção de conhecimentos, bem como de sua inserção social. É importante observar o que a criança pensa, como reage e o que tem a dizer acerca das experiências vivenciadas, ampliando assim as possibilidades de questionamentos para uma reflexão intensa e contínua do educador em torno das respostas apresentadas.

Moreira (1995) ressalta a importância do trabalho com o corpo no dia a dia da educação, visto que possibilita ao aluno refletir sobre seu corpo, sua relação com o ambiente e com os outros, reconhecendo ainda necessidades e desejos do corpo. O autor evidencia que esse trabalho é indispensável à compreensão de que a educação se processa no corpo todo, e não somente na cabeça dos 
alunos. Neste sentido, ressaltamos a necessidade de que o educador que atua na Educação Infantil assuma uma postura profissional de valorização do lúdico, do prazer e da participação, que fazem parte do que chamamos fazer pedagógico.

A criança é movimento em tudo o que faz, pensa e sente. O seu corpo presente é ativo em todas as situações e em todos os momentos. Ele, o corpo, dialoga todo o tempo com todos os que o cercam. [...] podemos notar que o corpo, por meio dos movimentos, denota sentimentos e emoções. (PORTO, 1995, p. 85).

Diante de uma perspectiva educacional inclusiva e integral, enfatizamos as abordagens de Porto (1995), que considera a relação professor/aluno como incentivadora de um desenvolvimento global, possibilitando ao aluno a aquisição de capacidades motoras, cognitivas, sociais e afetivas, numa perspectiva humana e sensível.

\section{Práticas inclusivas na Educação Infantil}

As atividades corporais estão intimamente relacionadas à afetividade e expressão da criança, e devem ser utilizadas para a integração das crianças entre si, com o ambiente educacional e com a sociedade em que atuam.

Consideramos as atividades corporais como forma de reconhecimento da diversidade, espaço de vida e comunicação consigo e com os outros, em busca de uma escola preocupada com a pessoa na sua totalidade, como ser crítico e flexível, visto que entendemos que a aprendizagem concreta se dá com o corpo todo (MARINHO et al., 2007).
De acordo com Silva (2008), as discussões acerca da inclusão tratam o tema com enfoques diferenciados, relacionados por vezes a todas as diferenças, mesmo aquelas que independem de necessidades especiais; e, outras vezes, toma como foco a inclusão, no ensino regular, dos alunos com deficiências específicas. Segundo a autora, promover a participação e o respeito às diferenças significa enriquecer o processo educacional, reconhecendo a importância do desenvolvimento das potencialidades, saberes, atitudes e competências de todos os alunos (SILVA, 2008, p. 15).

Muitas são as discussões e pesquisas sobre criança, inclusão e Educação Infantil que consideram as questões relacionadas aos debates sobre as práticas inclusivas (CERISARA, 1999; KRAMER, 2006; ROSEMBERG, 1999). Neste contexto, ressaltamos que as crianças são naturalmente acolhedoras e integradoras, o que de certa forma contribui para a atuação pedagógica do professor diante das diversidades. Buscamos, assim, refletir sobre a importância de se considerar o corpo e o movimento na Educação Infantil no âmbito da valorização e aceitação das diferenças.

A partir da prática pedagógica vivenciada nos anos de atuação na educação, verificamos que conflitos e discussões ocorrem em reuniões de pais e mesmo entre os professores, na ânsia de explicar, integrar e evitar possíveis discriminações. Busca-se também a compreensão do valor do ambiente educativo e das possibilidades de aprendizagem oferecidas para todas as crianças, porém muitas dessas preocupações e possibilidades são, por vezes, distantes das suas necessidades. Evidenciamos a importância de pensar a criança pela criança, dando voz às suas verdades e atentando às suas especificidades, como destacam os estudos da Sociologia da Infância (SARMENTO, 2002). 
Essas especificidades devem perpassar as análises diante da inclusão, visto que cada nível de ensino e cada ambiente educativo possuem características próprias, que necessitam ser levadas em consideração para a construção de uma prática pedagógica coerente.

De acordo com Marinho et al. (2007), devemos acreditar em mudanças, em uma escola melhor e mais significativa, que articula conhecimento e satisfação, alegria e descoberta, ludicidade e fantasia, corpo e mente; uma escola capaz de propor atividades desafiadoras, um ambiente de cooperação, integração, valores, desenvolvimento humano e aprendizagem para além da escolar.

$\mathrm{Na}$ busca de uma escola inclusiva, acreditamos que as práticas corporais e a ludicidade são imprescindíveis para uma prática pedagógica de qualidade, contextualizada e atenta à diversidade. Enfatizamos a importância da dimensão afetiva do ato educativo e da formação do profissional da educação para um novo direcionamento das práticas inclusivas, para um novo olhar diante das potencialidades e diversidades que acompanham os alunos. Ao abordarmos o ato de observar como componente fundamental de uma atividade educacional integral e humana, encontramos em Gonçalves (1994, p. 103) importantes contribuições acerca das manifestações corporais carentes de atenção por parte do educador:

A linguagem corporal que se expressa no olhar, no riso, na expressão dos lábios, nas mãos, na postura, enfim, em toda a presença do corpo, permite uma compreensão do outro de forma direta, sem intermédio do pensamento, uma apreensão do sentido de seu gesto e da expressão facial, de sua emoção e de seus sentimentos, de sua posição no mundo.
Como educadores devemos estar preparados para abandonar padrões de aprendizagens estabelecidos historicamente como corretos e ideais, na busca de uma educação que considere a diversidade entre as pessoas como um aspecto desafiador, potencializador e enriquecedor do processo de ensinar e aprender.

\section{A formação inicial do professor de Educação Infantil: prática corporal e educação inclusiva}

Tendo como pressuposto que a educação inclusiva requer do profissional uma formação específica (MICHELS, 2006), direcionada à compreensão do educar e atenta à diversidade entre os educandos e às especificidades de cada ser, verificamos lacunas na formação inicial dos professores: as áreas de conhecimento pouco se relacionam, conhecimentos são fragmentados e minimizados para aceleração do processo de formação, bem como há pouco ou nenhum estudo relacionado às práticas corporais.

Os profissionais que atuam na Educação Infantil têm formação em nível médio ou no Curso de Pedagogia, conforme indica a legislação educacional vigente, a LDB $n^{\circ}$ 9394/1996. Considerando a formação obtida em ambos os níveis de ensino, verificamos o descaso em relação às práticas corporais na formação de professores. Os currículos desses cursos geralmente não contemplam disciplinas específicas para o desenvolvimento de conhecimentos sobre o corpo, o movimento e a ludicidade, e quando elas existem apresentam conceitos por vezes fragmentados, disciplinadores e rígidos, sem a possibilidade de uma discussão acerca da totalidade corporal relacionada à aprendizagem, ou sem elos com as demais áreas do currículo de formação. 
As Diretrizes Curriculares Nacionais para a Formação de Professores da Educação Básica, em seu artigo $2^{\circ}$, referente à orientação à formação para a atividade docente, têm como um dos aspectos a serem observados o acolhimento e o trato à diversidade, porém observamos que a formação do profissional da educação tem dispensado pouca atenção a esse critério.

O Referencial Curricular Nacional para a Educação Infantil - RCNEI (BRASIL, 1998-2000), além de apresentar algumas considerações superficiais sobre a prática corporal, o brincar e o desenvolvimento integral da criança, não intensifica as discussões e não apresenta subsídios para o aprimoramento da atuação do professor. Ao abordar a inclusão, Amaral (2002, p. 239) afirma:

Na contramão de um longo processo histórico de reversão de ações discriminatórias, a temática da inclusão nos vem sido oferecida como um "grande salto qualitativo" no caminho da humanidade. Contraponho "processo" a "salto" por entender que, neste ultimo, está implícita uma mudança brusca no percurso. Ora, todos sabemos a força dos elementos históricos em todas as experiências individuais e sociais.

Consideramos a validade e a necessidade de práticas fortalecidas e adequadas para uma educação inclusiva, porém não podemos deixar de considerar também o contexto no qual a escola se desenvolveu, para que os encaminhamentos necessários sejam construídos com coerência e embasamento teórico apropriado, que conduza a um processo de reconstrução do ato educativo.

Souza, citado por Oliveira (2002, p. 266), esclarece que:

Professores, como profissionais qualificados, têm o direito e a obrigação de se desenvolverem continuamente. Entretanto, projetos individuais de formação contínua devem ser parte de um projeto mais amplo, no nível da escola. A preocupação com a qualidade do ensino deve ser encarada como uma questão coletiva, não como um problema individual de professores isolados.

Gonçalves (1994) enfatiza as marcas culturais impressas no indivíduo e representadas em seu corpo. Cada corpo, segundo a autora, reflete não somente sua singularidade pessoal, mas as características de um grupo ao qual pertence. Assim sendo, podemos frizar a complexidade do ato educativo bem como as múltiplas dimensões atreladas à formação do professor.

Segundo a Declaração de Salamanca (1994), devemos buscar uma Pedagogia centralizada na criança, em que a diversidade e as diferenças existentes entre elas sejam consideradas e respeitadas, sendo suas necessidades educacionais, acima de tudo, supridas. No referido documento são destacados os seguintes aspectos em relação à educação da criança:

- toda criança tem direito fundamental à educação, e deve ser dada a oportunidade de atingir e manter o nível adequado de aprendizagem,

- toda criança possui características, interesses, habilidades e necessidades de aprendizagem que são únicas,

- sistemas educacionais deveriam ser designados e programas educacionais deveriam ser implementados no sentido de se levar em conta a vasta diversidade de tais características e necessidades,

- aqueles com necessidades educacionais especiais devem ter acesso à escola regular, que deveria acomodá-los dentro de uma Pedagogia centrada na criança, capaz de satisfazer a tais necessidades,

- escolas regulares que possuam tal orientação inclusiva constituem os meios 
mais eficazes de combater atitudes discriminatórias criando-se comunidades acolhedoras, construindo uma sociedade inclusiva e alcançando educação para todos; além disso, tais escolas provêem uma educação efetiva à maioria das crianças e aprimoram a eficiência e, em última instância, o custo da eficácia de todo o sistema educacional. (Disponível em http://portal.mec.gov.br/seesp/arquivos/pdf/salamanca.pdf).

Assim, verificamos que conhecer a criança e seu envolvimento com a atividade lúdica se faz necessário diante de uma educação coerente com a formação de seres sociais capazes de pensar, agir e desenvolver-se na perspectiva de uma escola que prepara para a vida. De acordo com Oliveira (2002, p. 220):

O professor pode criar situações que possibilitem à criança imergir em atividades significativas em que busque explicar o mundo em que vive e a si mesma. Essas situações - com seus cenários, participantes e papéis - são recursos para a formação de habilidades e a construção de conceitos e valores por parte dela.

Considerando as abordagens de Mendes (2006), destacamos que as práticas inclusivas devem refletir um trabalho coerente e verdadeiramente inclusivo, superando uma visão meramente integradora. As escolas devem partir para uma prática de efetiva inclusão e participação, onde o educador seja capaz de perceber a realidade em que está inserido, e quais suas reais possibilidades de ação naquele contexto.

\section{Prática pedagógica contextualizada e formação continuada: na busca de soluções}

A inclusão, bem como os demais temas carentes de atenção e estudos no ambiente escolar, nos mostra que a escola permanece desvinculada de um contexto social amplo e diverso, fruto de um sistema econômico baseado na produção e na técnica, com estruturas físicas destinadas a um padrão de aluno tido como "normal” e produtivo. Para Oliveira (2002, p. 250),
A efetiva operacionalização das necessá- rias mudanças no cotidiano escolar para atendimento das crianças com necessi- dades educativas especiais em creches e pré-escolas parte de duas considerações: a de que todas as crianças sem exceção têm eficiências e deficiências em suas formas de se relacionar com o mundo e a de que devemos trabalhar para a ampliação de suas eficiências.

Muitos são os aspectos a serem revistos, porém para que possamos nos integrar a uma necessidade urgente de humanização da escola e da sociedade, os primeiros passos precisam partir do professor, que para tal carece de melhor formação inicial e espaços constantes de discussão e aprendizagem, que caracterizem uma formação continuada coerente e significativa.

Tal formação deve ser voltada para um profissional capaz de discutir os fatos que ocorrem em sua realidade educacional, lutar pela melhoria das condições de trabalho, principalmente quando estas se relacionam à inclusão de alunos com necessidades especiais, visto que diante de suas especificidades eles necessitam de recursos diferenciados, sejam estes humanos ou materiais. Enfim, um professor capaz de integrar a 
todos em uma prática pedagógica humanizante, que esteja atento às diversidades e à construção do conhecimento. Delval (1998, p. 235), ao tratar da formação docente, ressalta que o professor:

Precisa conhecer os condicionantes sociológicos da educação e como as práticas educativas e as teorias da educação dependem de fatores sociais; precisa compreender, em poucas palavras, que a educação é um fenômeno social [...] é preciso que o professor conheça as relações entre educação e classes sociais, as significações das diferentes práticas educacionais, o papel social dos professores, os condicionantes sociais da aprendizagem, etc.

\section{A legislação específica da Educação} Especial trata das características de algumas deficiências, porém com maiores esclarecimentos acerca da surdez. Há urgência de romper-se o paradigma das receitas de como educar a criança com necessidades educativas especiais, visto que cada ser é único, e a prática deve ser constituída mediante as características apresentadas pela criança.

Na busca incessante do que consideramos ser uma educação verdadeira e uma escola acolhedora, acreditamos que a formação consistente, coerente, crítica e humana pode sim transformar as práticas pedagógicas, rever conceitos como aprendizagem, inclusão e avaliação. Pode, também, gerar discussões acerca do que Demo (2004) denomina de como gerenciar as diferenças, diante de uma escola e uma sociedade que historicamente aprendeu a evidenciar as diferenças na busca da seletividade, dos resultados e da racionalização. Para Oliveira (2002, p. 246):

A formação continuada dos professores deve capacitá-los para conhecer melhor o que hoje se sabe a respeito das possibilidades de trabalho pedagógico de promoção do desenvolvimento de todas as crianças com necessidades educacionais especiais, bem como para auxiliar essas crianças na construção de conhecimentos cada vez mais ampliados e significativos acerca do mundo e de si mesmas.

Alguns professores preferem que as crianças com necessidades educativas especiais obtenham apenas atendimento especializado, mediante a angústia e a crença de que não podem atender a essas especificidades, e de que não foram preparados para tal desafio. Oliveira (2002) enfatiza que essas crianças são iguais às outras e que elas podem enriquecer a diversidade do processo de aprendizagem. Cabe ao educador a busca de estratégias apropriadas, rompendo o paradigma de que a homogeneidade é condição para o bom ensino. Há uma grande necessidade, tanto do ser humano quanto da sociedade, em conviver, valorizar, respeitar e aprender com as diferenças.

\section{Considerações finais}

A atuação profissional do educador, de acordo com Tardif (2000), encontra-se constantemente permeada por vivências enquanto aluno, bem como por experiências relacionadas ao contexto educacional do qual fez e faz parte.

Ao tratarmos de práticas inclusivas, verificamos claramente que alguns receios e inseguranças do educador diante do desafio da educação inclusiva esbarram em preconceitos já estabelecidos em relação às possibilidades de aprendizagem e ao desenvolvimento dos alunos que não se adaptam ao que até então era tido como um padrão a ser seguido por todos na escola. Lutamos diariamente contra uma sociedade excludente e contra nossos próprios medos.

Verificamos que além de uma formação técnica, referente à inclusão, precisam 
ser fortalecidas as atividades e os estudos direcionados ao resgate do valor da pessoa humana, da sensibilidade e da empatia.

Cremos na riqueza de possibilidades da diversidade, no respeito mútuo e na humanização; buscamos a coerência do processo de inclusão atento a cada caso, a cada criança, a cada necessidade e a cada professor, diante das possibilidades de aprendizagens, rompendo padrões e conceitos. Cremos na educação.

\section{Referências}

AMARAL, L. A. Diferenças, estigma e preconceito: o desafio da inclusão. In: OLIVEIRA, M. K. de (Org.). Psicologia, educação e as temáticas da vida contemporânea. São Paulo: Moderna, 2002.

BARBOSA, M. L. P. Práticas escolares: aprendizagem e normalização dos corpos. Porto Alegre, UFRGS, 2006. Dissertação (Mestrado em Educação) Programa de PósGraduação em Educação, Universidade Federal do Rio Grande do Sul, Porto Alegre, 2006.

BRASIL. Secretaria de Educação Fundamental. Referencial Curricular Nacional para a Educação Infantil. Brasília: MEC/ SEF, 3 v, 1998.

\section{Referencial Curricular Nacio-} nal para a Educação Infantil: estratégias e orientações para a educação de crianças com necessidades educacionais especiais. Brasília: Ministério da Educação - MEC, 2000. Disponível em: http://portal.mec.gov.br/seb/ arquivos/pdf/eduinf_esp_ref.pdf . Acesso em 28 de julho de 2011.

CAMBI, F. História da pedagogia. São Paulo: Editora Unesp, 1999.
CARVALHO, R. S. Educação Infantil: práticas escolares e disciplinamento dos corpos. Porto Alegre, UFRGS, 2005. Dissertação (Mestrado em Educação) Programa de PósGraduação em Educação, Universidade Federal do Rio Grande do Sul, Porto Alegre, 2005.

CARVALHO, V. S. Pedagogia levada a sério. Rio de Janeiro: Wak, 2003.

CERISARA, A. B. Educar e cuidar: por onde anda a educação infantil? Revista Perspectiva, v.17, n. Especial, p. 11 - 21, jul./dez. Florianópolis: 1999.

DECLARAÇÃO DE SALAMANCA. Sobre princípios, políticas e práticas na área das necessidades educativas especiais. UNESCO, 1994. Disponível em: http://portal.mec. gov.br/seesp/arquivos/pdf/salamanca.pdf. Acesso em 20 de julho de 2011.

DEMO, P. Universidade, aprendizagem e avaliação: horizontes reconstruídos. Porto Alegre: Mediação, 2004.

\section{DELVAL, J. Aprender na vida e aprender} na escola. Porto Alegre: Artmed, 2001.

DIRETRIZES Curriculares Nacionais para a formação de professores, Resolução CNE/ CP N ${ }^{\circ}$ 1, de 18 de Fevereiro de 2002. Disponível em: http://portal.mec.gov.br/seesp/ arquivos/pdf/res1_2.pdf. Acesso em 15 de julho de 2011.

DORNELLES, L. V. Infâncias que nos escapam: da criança na rua à criança cyber. Petrópolis: Vozes, 2005.

FOULCAULT, M. Vigiar e punir: nascimento da prisão. Petrópolis: Vozes, 2007.

GARANHANI, M. C. Procedimentos para a pesquisa de práticas pedagógicas no cotidiano da Educação Infantil: relato de investigação. Diálogo Educacional, v. 6, n. 19, p. 65-80, set/dez. 2006. 
GONÇALVES, M. A. S. Sentir, pensar e agir: corporeidade e educação. Campinas: Papirus, 1994.

KRAMER, S. Com a pré-escola nas mãos: uma alternativa curricular para a educação infantil. São Paulo: Ática, 1993.

As crianças de 0 a 6 anos nas políticas educacionais no Brasil: educação infantil e /é fundamental. Educação e Sociedade, vol. 27, n. 96 - Especial, p. 797-818, Campinas: 2006 . Disponível em: http://www. cedes.unicamp.br

LE BOULCH, J. O corpo na escola do século XXI: práticas corporais. Tradução de Cristiane Hirata. São Paulo: Phorte, 2008.

MARCELLINO, N. C. (Org.). Lúdico, educação e Educação Física. Ijuí: Ed. Unijuí, 2003.

MARINHO, H. R. B. et al. Pedagogia do movimento: universo lúdico e psicomotricidade. Curitiba: Ibpex, 2007.

MENDES, E. G. A radicalização do debate sobre inclusão escolar no Brasil. Revista Brasileira de Educação, n. 33. set/dez, 2006.

MICHELS, M. H. Gestão, formação docente e inclusão: eixos da reforma educacional brasileira que atribuem contornos à organização escolar. Revista Brasileira de Educação, v. 11, n. 33 set./dez. 2006.

MOREIRA, W. W. Corpo presente, corpo pressente. Campinas: Papirus, 1995.

MOYLES, J. Só brincar? O papel do brincar na educação infantil. Porto Alegre: Artmed, 2002.

OLIVEIRA, M. K. (Org.). Psicologia, educação e as temáticas da vida contemporânea. São Paulo: Moderna, 2002.
OLIVEIRA, Z. R. Educação infantil: fundamentos e métodos. São Paulo: Cortez, 2002.

OLIVIER, G. G. F. Lúdico e escola: entre a obrigação e o prazer. In: MARCELLINO, N. C. (Org.). Lúdico, educação e educação física. Ijuí: Ed. Unijuí, 2003.

PORTO, E. T. R. Mensagens corporais na pré-escola: um discurso não compreendido. In: MOREIRA, W. W. (Org). Corpo presente. Campinas: Papirus, 1995.

QUEIROZ, N. L. N. Brincadeira e desenvolvimento infantil: um olhar sociocultural construtivista. Paidéia, 2008, p. 169-179.

ROSENBERG, F. Expansão da Educação Infantil e processos de exclusão. Cadernos de Pesquisa, São Paulo, n. 107, julho de 1999.

SARMENTO, M. J. Infância, exclusão social e educação como utopia realizável. Educação e Sociedade, ano 23, n.78, abril/2002.

. Gerações e alteridade: interrogações a partir da sociologia da infância. Educação e Sociedade, Campinas, vol.26, n.91, p.361 - 378, maio/ago. 2005.

. Culturas infantis e interculturalidade. In: DORNELLES, L. V. (Org.). Produzindo pedagogias interculturais na infância. Petrópolis: Vozes, 2007.

SARMENTO, M. J; GOUVEIA, M. C. S. (Orgs.) Estudos da infância: educação e práticas sociais. Petrópolis: Vozes, 2008.

SILVA, L. M. G. Educação Especial e inclusão escolar sob a perspectiva legal. Simpósio de Estado e Políticas - UFU. Uberlândia: 2008. Disponível em: http://www.simposioestadopoliticas.ufu.br/imagens/anais/pdf/ BP05.pdf Acesso em 20 de julho de 2011.

SOUZA, P. N. P. Como entender e aplicar a nova LDB. São Paulo: Thomson Learning, 2002. 
TARDIF, M. Saberes profissionais dos professores e conhecimentos universitários: elementos para uma epistemologia da prática profissional dos professores e suas conseqüências em relação à formação para o magistério. Revista Brasileira de Educação, n. 13. jan./fev./mar/abr. 2000.

Enviado em: 16/05/2011

Aceito em: 23/09/2011 